\title{
Research Square \\ Five Decades of Information on Canine \\ Environmental Pollutant Exposure: A Scientometric Analysis
}

Albert Raul Avila ( $\square$ albertravila@javeriana.edu.co )

Pontificia Universidad Javeriana https://orcid.org/0000-0002-8885-0856

\section{Laura Lizeth Prieto}

Pontificia Universidad Javeriana

Andrea Luna-Acosta

Pontificia Universidad Javeriana

\section{Research Article}

Keywords: Scientometricanalysis, Environmental contamination, Exposure, Biological effects, Dogs.

Posted Date: March 3rd, 2022

DOI: https://doi.org/10.21203/rs.3.rs-1328390/v1

License: (c) (i) This work is licensed under a Creative Commons Attribution 4.0 International License.

Read Full License 


\section{Abstract}

In recent decades, there has been great concern associated with environmental pollution as a risk factor for the development of different diseases in humans, and the canine species has been considered one of the closest sentinel animal models to evaluate these effects. In this sense, a review was carried out to identify the advances and information gaps on this topic. For this, a Scientometric approach was used, with the application of quantitative statistical analysis to bibliography. Results revealed that there has been in increase in scientific production during the last 20 years in journals such as Science of the Total Environment, Journal of Allergy and Clinical Immunology and Environmental Health Perspectives, highlighting the participation of authors such as Sonne, Dietz and Letcher . In this way, the United States, Denmark, and Canada, as well as Universities such as Ehme, Aarhus, Hokkaido and California, are considered the most relevant countries and institutional affiliations in scientific production and collaboration in relation to this topic. In the same way, there is a growing interest in the development of various lines of research related to persistent organic compounds (PCBs, PBDEs) and heavy metals ( $\mathrm{Hg}$ mainly), using dogs as sentinels, as well as the evaluation of new sources of contamination related to microorganisms. Finally, issues related to air pollutants, particulate matter and asthma appear as new areas of research, in which the canine sentinel model may show promise for the evaluation of its effects.

\section{Introduction}

Environmental pollutants are compounds whose states and physicochemical characteristics (organic or inorganic) allow them to come into contact with individuals, in such a way that they can cause adverse effects both for the health of organisms and for exposed ecosystems (Thompson and Darwish 2019). This broad group includes persistent organic compounds (POPs), such as polychlorinated biphenyls (PCBs), polycyclic aromatic hydrocarbons (PAHs), perfluorinated compounds (PFCs), pharmaceuticals and personal care products (PPCPs), radioactive elements, electronic waste, plastics, heavy metals, and nanoparticles, among others (Pastorinho and Sousa 2020). Currently, there is growing evidence about the considerable increase of these elements, both in their concentrations and in their geographical distribution in recent years (Córdoba 2006; Carriquiriborde 2021). Despite the fact that some of these compounds occur naturally in the earth's biogeochemical processes, contemporary anthropogenic activities, such as intensive industrial activities, land-use changes, mining and incineration of fossil fuel, are considered as main factors that mobilize these chemicals into ecosystems (Conti 2008; Selin 2009). Once liberated in the environment, these compounds can be biotransformed, bioaccumulated or biomagnified in exposed organisms (Andreoli and Sprovieri 2017; Boisvert et al. 2019). Among the main routes of exposure of these pollutants in animals and humans are diet, soil, water, and air (Laks 2007; Thompson and Darwish 2019), producing a wide range of biological effects on exposed organisms. Therefore, the need arises to analyze the links that environmental pollutants have on human and animal health in recent years (Sonne et al. 2020).

In recent years, there has been a great concern associated with environmental pollution as a risk factor for the development of different diseases in the human species (Chen et al. 2007; Laks 2007; Ipenza 
2012; Obiri et al. 2016; Schutzmeier et al. 2017), which is why it is necessary to develop, guide and evaluate new research models that address this problem prospectively, allowing the generation of early warnings for decision-making. Different animals have been used for the evaluation of the contamination of environmental pollutants such as mercury during the last 20 to 25 years. Domestic livestock and poultry (Chibunda et al. 2009), for example, have been evaluated in regions of Tanzania in order to determine $\mathrm{Hg}$ concentrations in liver and kidney samples in areas impacted by gold mining, finding high levels of this metal in the organs of these animals $(0.436$ and $0.820 \mathrm{mg} / \mathrm{kg}$ respectively), thus allowing to suggest, based on scientific evidence, a better control of the emission levels of this metal on this anthropogenic activity, and thus protect human health against the adverse effects already described for this metal, by avoiding the raising of these animals in its surroundings. However, regarding human health analyzes, most of these species do not show comparative similarities between the metabolic and contaminant exposure phases in humans, as the canine species would (Parker et al. 2006). Canines present very similar enzymatic and metabolic systems, a physiologically compressed lifetime (Wang et al. 2020) and are free of risk factors for lifestyle-related diseases (Parker et al. 2006; Abbott 2017; Fuentes et al. 2018), a situation that usually occurs in humans. In addition, dogs share their same environment, responding to many toxic factors in an analogous way.

Despite this interesting point of view, a series of questions still arise such as the racial differences inherent to the species that would limit to some extent the total extrapolation of the data obtained in the evaluation of mercury contamination, consequently, the variability between races. could express specific phenotypic traits between the incidence of genetic diseases and specific metabolic processes, research that has already been documented and specified for the vast majority of races of this species (Oddone and Rodriguez 2010), for example, neurotoxic processes to certain drugs in border collies due to mutations on the MDR1 gene or sensitivity to phenothiazines in brachycephalic dogs (Botana 2016) to name a few. Despite the aforementioned, the dog continues to be a valuable resource for modeling complex studies (Ostrander and Wayne 2005), which is why it is necessary to encourage and later develop investigations that allow standardizing and improving the robust modeling of this species, in order to strengthen these statements.

Lately, technological, and statistical advances have made possible to evaluate the state of the art of different topics of interest in a more objective way, managing to identify the main findings, thematic trends, scientific production networks and information gaps on scientific study. Scientometrics, a quantitative statistical analysis tool, is frequently used in the fields of publishing and information science to provide quantitative analyzes of academic literature. Such analysis is now used in most scientific fields to assess the growth, leading authors, and trends of a scientific community (Aria and Cuccurullo 2017; Pranckute 2021). In this sense, and despite the progress of various research, no scientometric analyzes have been carried yet regarding the effects that exposure to different environmental pollutants would have on canines.

The main objective of this review was to carry out a scientometrics analysis of the study of current environmental pollutants and their effects on canines. This will allow to identify the advances and 
information gaps on canines regarding the monitoring and evaluation of the chemical compounds that are being released and accumulating in the ecosystems, and that for decades have been directly affecting the different spectra of the health of both the human being and exposed organisms. This will allow the development of guidelines for research studies in canines as sentinel species, and this scientometric review would be ca first approach on the state of the art in this research line during the last five decades, focusing particularly on research hotspots.

\section{Materials And Methods}

In the present scientometric analysis, an advanced search was carried out in the Scopus database, under the following key terms: "Dogs" and "Environmental pollutants". This based on the fact that they were the words in which the most results were generated on articles, reviews and books in this database. The Scopus database is one of the most important sources of scientific and medical information worldwide (Aria and Cuccurullo 2017; Pranckute 2021), currently considered one of the most complete and reliable databases by the scientific community, even superior to other databases such as Web of Science (Harzing 2016; Zhu et al. 2020). The search covered the years 1969, the year in which evidence related to this topic was found for the first time in this database, until September 6, 2021, the date the corresponding download was made (Annex 2). In order to investigate the most relevant topics, trends and the current situation in the field of the effects that the main environmental pollutants would have on canines, documentary typologies in English indexed to this database were compiled, such as cited journals, chapters of books and review articles. The information on the authors, keywords, years of publication and institutions, among others, were extracted by exporting the data in BibTex format from the Scopus database.

To perform the analysis of the compiled data, the statistical software R (R Foundation for Statistical Computing) version 4.1.1 was used, and the Bibliometrix 3.1 package, an open-source tool for quantitative research in scientometric and bibliometrics that includes all the main bibliometric methods of analysis, such as data matrices for co-citations, couplings, production analysis and scientific collaboration, and joint word analysis (Aria and Cuccurullo 2017).

Research carried out in databases such as those presented in this review, often requires filtering, corrections, and normalizations for the reliability of their results, thus avoiding that some data could be underrepresented or overrepresented. Therefore, some modifications were necessary for the standardization and normalization of the references in the file downloaded from the Scopus database, double checking the verification of the data used, thus avoiding alphabetical biases. Similarly, some other corrections were made such as spelling errors, inconsistencies, and the appearance of homonyms on the plain text downloaded in that format.

All the images, tables, figures, and maps used were extracted directly from the Biblioshiny graphical interface without any editing by another program. It should be made clear that, in the reviewed scientific 
literature, no scientometric analyzes were found related to the exposure of environmental pollutants in canines, suggesting this document as a first approach to this area of study in relation to scientometrics.

\section{Results}

\subsection{Documentary production}

A total of 372 documents were extracted from the Scopus database, distributed in 316 articles, 5 book chapters and 51 review articles that were related to the effects of environmental pollutants in canines, taking them as input for the corresponding scientometric analyzes. In this analysis, a collaboration index of 4.8 per author was obtained, a value that corresponds to the quotient between the number of authors and the number of articles published (Aleixandre et al. 2017). Likewise, an average of 29.6 citations per document and 17,955 citations for the total files analyzed were obtained. The number of articles published in this field of research fluctuated from the production of the first two articles for 1969 in this database, to 22 documents for 2021 (Figure 1), showing a large increase for this last decade, with an average annual growth rate of 2.93\%, being the years 2015 (22 documents) and 2019 (23) the ones with the highest production in this research area.

Figure 1 Annual scientific production on research related to environmental pollutants in the canine species from 1969 to 2021

Figure 1 shows that the period analyzed in this review can be divided into three main stages. The first comprised between the years 1969-1988 (65 documents), which shows a slight increase in the number of published articles. The second stage between 1989-2001 (46 documents), a time when the number of publications remains with an average trend compared to the previous period. The third stage comprised between 2002-2021 (261 documents), a time in which a more rapid development, consolidation and average annual production is evidenced above the aforementioned years.

\subsection{Analysis of publication sources}

Regarding the most relevant publication sources for the authors, it was found that the journals that occupy the first three places are Science of the Total Environment, Environmental Science and Technology and Environmental Health Perspectives with 24, 20 and 16 articles for each one of them respectively (Figure 2). This was determined by analyzing Bradford's law of dispersion of the scientific literature and distribution, a law that estimates exponentially decreasing returns from the search for references in scientific journals (Aria and Cuccurullo, 2017).

Figure 2 Most relevant publication sources determined according to Bradford's law of dispersion of the scientific literature

It was evaluated that the most cited local sources for the development of this type of research are in descending order, the journals Science of the Total Environment, Journal of Allergy and Clinical 
Immunology and Environmental Health Perspectives, having an exponential trend to continue growing during the course of this last decade according to the trend pattern obtained (Annex 1).

\subsection{Author analysis}

On the other hand, to determine the impact factor of the authors, the $\mathrm{H}$ index was taken into account, a system proposed by the University of California that is frequently used to measure the professional quality of scientists and researchers; depending on the number of citations, the articles have received (Aria and Cuccurullo 2017). Consequently, the top 10 authors with the greatest scientific production in this field were taken as the top, thus making a relationship between production time and the number of studies that have been developed over time based on the issue of environmental pollutants in canines (Figure 3).

Figure 3 Production of the 10 main authors over time. The straight lines indicate the continuity of studies in relation to time

In Figure 3 it can be seen that Heyder Joachim was the author who initiated the investigations in relation to contaminants in canines in the year 1992 to 1999, with this being relevant for studies that have been consolidated by authors who today stand out in the field. Similarly, Sonne C. Dietz R. and Letcher R. stand out as the most active authors from 2005 to 2021 with an average scientific production rate of more than five articles produced annually, a very similar average for the three of them during the years cited above. Additionally, new authors such as Nomiyaka, Mizukawa and Kirkegaard were identified as having had a notable role in the latest research towards the last decade.

In Figure 4 of three fields or tripartite, the relationships between the keywords, the authors and the country of origin are observed, which were graphed in relation to the generation of a top in the following way: the top five of countries, the top ten of authors and the top ten of the most prominent keywords according to the analysis, this in order to obtain their interconnections and direct relationships that link them.

Figure 4 Tripartite graph on the effects of environmental pollutants on canines. Left field (Keywords), Middle field (Authors), Right field (Countries)

Figure 4 shows a clear relationship between the authors Sonne, Dietz and Letcher with keywords such as Dogs, Effects and Environment, which suggests the trend of these kind of studies with the authors and their countries of institutional affiliation respectively. It was found that the authors Sonne, Dietz and Letcher, as well as the countries Denmark, USA, Canada, and Japan are considered as the main representatives in the research carried out on environmental pollutants and their effects on the canine species.

Likewise, it is observed that authors such as Nomiyama, Kirkergaard, and Mizukawa have had a prominent role in these issues with affiliations to eastern countries such as Japan and China, this being convenient when managing to broaden the spectrum of this type of research lines in Asian countries. As for the keywords with the highest number of repetitions cited by the authors, the following are found: 
asthma, pollution and air, which will probably come to be considered a trend in relation to air pollution and emerging pollutants in this research line.

\subsection{Institutional Affiliation Analysis}

The results showed that the University of Ehme (Japan) have a total of 16 publications on environmental pollutants in canines, while the University of Aarhus (Denmark), the University of Hokkaido (Japan) and the University of California (USA) showed a total of 14 publications for each one, these universities being the top of the most relevant institutional affiliations for the development of this type of studies (Figure 5). However, other leading universities in the world such as Harvard Medical School and the University of Copenhagen also appear as affiliations interested in approaching this type of research.

Figure 5 Most important affiliations for the development of this kind of studies

As for the countries with the highest production in relation to this issue, there are the United States, Canada, China, and Denmark with a total of 407, 51, 54 and 43 scientific productions for each of them respectively over time, exhibiting greater strength of collaboration between countries such as the United States with Denmark (4 edges), Australia (5 edges), Sweden (2 edges) and China (6 edges) (Figure 6 ). Despite this, Canada has a higher rate of collaboration with Denmark (17 edges), which is higher than that observed in comparison with the United States. In this way, the countries of the northern hemisphere are the ones that tend to create the most collaboration networks and therefore one of the most cited for the development and consolidation of this type of subject.

Figure 6 Map of production and collaboration between countries. The edges indicate the networks of nodes that exist between countries for the development of this type of research; the thicker lines indicate the existence of a stronger collaboration between countries. The conventions on the left side indicate the average number of documents produced for each country

\subsection{Network analysis}

\subsubsection{Keyword analysis}

Keyword analysis is a fundamental tool to identify the most relevant terms in research development (Harzing 2016; Zhu et al. 2020). In this sense, the Biblioshiny interface generated a top 30 of words according to their frequency of use in the articles analyzed, which required a series of transformations. In the first measure, Louvain's grouping algorithm was applied to this number of words, which performs and guarantees an evaluation of the data set, comparing the density of edges that are present inside or outside the community (Aria and Cuccurullo 2017). Next, the results were cleaned up in order to eliminate synonymous words and terms not associated with the topic, the colors indicating the association between these words (Figure 7).

Figure 7. Association networks between the words most used by the authors between 1963 and 2021 
In Figure 7, it was possible to identify three groups with the highest representation of frequencies for the keywords. The largest group, represented in green, focuses on air pollution, asthma, and children, where there is a clear relationship with the group of allergens, allergies and particulate matter. The next group, represented in purple, comprises the effects of halogenated organic pesticides and heavy metals such as mercury, and their clear relationship with dogs and sled dogs on organs such as the kidney and liver. The third group the smallest and is represented in blue, focusing its research on biological contaminants such as microorganisms.

Delving into this topic, the words with the highest concurrence, that is, with the largest node size, that were identified in the graphical interface of the package through data analysis were the following: asthma, air pollution, organochlorine pesticides, canines, and air pollutants. Therefore, it could be considered that these terms are a trend in the development of this type of study due to the frequency of repetition. In the same way, but not less important, within the nodes with the lowest frequency occurrence the words Flame retardants (PCBs), Hair and $q P C R$ were found, possibly due to a smaller number of related studies, which could tentatively be revealing in part, that these words are considered as new fields of study in relation to the study of canines and environmental pollutants.

\subsubsection{Co-authorship analysis}

The identification of the most cited publications revealed that the top authors and the key topics of interest in the investigation of the effects of environmental pollutants on the canine species usually have a pattern of association that results in a wide network of co-citations. The inclusion criteria for this review were the top 50 of the most cited authors using a series of criteria applied by the interface. For example, the selected authors were those who participated in at least five publications. Each node used corresponds to an author, while the ratio of node sizes represents the number of posts generated. Subsequently, and previous filtering adjustments and spelling corrections, Louvain's algorithm was used for the grouping of the data obtained, obtaining an estimate of the grouping of nodes represented in Figure 8.

Figure 8. Citation networks on the effects of environmental pollutants on canines between 1963 and 2021

The results of this graph showed the most representative authors by grouping Sonne, Dietz, Letcher (grouping in red), Wang, Zhang (grouping in green) and Chen, Wilson (grouping in blue) as the most prominent authors of each group. In this sense, Sonne, Wang and Chen continue to be the most representative nodes, due to the fact that they are the authors with the highest frequency of citation for this analysis. Likewise, the existence of a series of networks is observed among them that clearly shows a close collaboration between their studies.

\section{Hot Issues And Topics Of Lasting Impacts}

\subsection{Hot issues}


The scientometric analysis developed allowed a better understanding of the knowledge of environmental pollutants on canines, helping to understand even better the relationships, patterns and trends that exist in this recent field of research (NCR 1991; Poma et al. 2020; Sonne et al. 2020). These components have had greater research interest in recent decades (Figure 1), probably due to the metabolic and adaptive similarities with human beings, and their advantage of showing the phenomena of affinity, efficacy and pathogenic action that these pollutants would have on a large part of the exposed organic systems (Gupta 2018; Pastorinho and Sousa 2020), in addition to having achieved validation as sentinel models in typical regions of the planet such as the Arctic as described by several authors (Kirkegaard 2009; Abbott 2017; Letcher et al. 2017; Sonne et al. 2020). Despite this, it should be mentioned that the study of environmental pollutants in canines has been a subject of recent appearance that has been slowly consolidating, becoming increasingly stronger by different disciplines. Therefore, scientific communities are invited to pay more attention and interest in the validation of sentinel organisms due to the advantages they provide in relation to studies in humans, for example, especially in regions of the planet where short-term results and greater precision are required.

In relation to the data set obtained, a low amount of bibliographic material was evidenced that was compiled with the key terms previously referenced in this document. Therefore, it is necessary to promote the integration of this type of research lines with new approaches that allow growth, development and consolidation for the following years, a situation that has already been happening with the collaborative efforts of multiple disciplines such as those proposed by One Health, where ecologists, veterinary and human medical sciences have a considerable role.

In the same way it must be taken into account that it is a topic that has been in research since 1969, but only the last 13 years have been more dedicated to the development and consolidation of the effects of environmental pollutants in canines (Figure 1), which currently turns out to be a research area that allows increasing the spectrum of the problems related to environmental pollution and climate change on planetary health (Pastorinho and Sousa 2020; Sonne et al. 2020).

The scientometric analysis developed in this study very surely allowed a better understanding of the knowledge of environmental pollutants on canines, helping to understand even better the relationships, patterns and trends that exist in this recent field of research (NCR 1991; Poma et al. 2020; Sonne et al. 2020). In this sense, the development of scientometric studies in relation to environmental pollutants, and lately climate change, in human beings have allowed the approach and evaluation of the current state of these research lines during the last decades, such as other scientometric analyzes developed by Dhital and Rupakheti (2019); Lie et al. (2018) and Sweileh (2020) in other similar subjects.

Studies between animals and environmental pollutants could have greater research interest in the last decade (Figure 1), probably due to new studies that have shown metabolic, genetic, and adaptive similarities with human beings, and the affinity, efficacy, and pathogenic action that these pollutants have on a large part of the exposed organic systems in canines (Gupta 2018; Pastorinho and Sousa 2020). In addition, canines as sentinel species for human health have been validated recently in specific regions of 
the planet such as the Arctic as described by several authors (Kirkegaard 2009; Abbott 2017; Letcher et al. 2017; Sonne et al. 2020).

Regarding the top of the analyzed journals in this analysis (Figure 2) these are considered by the scientific community as the bibliographic sources with the most information reported for this class of studies, therefore, researchers with a great interest in the development of this type of research, it is recommended to refer to these sources to make their pertinent updates on the subject. However, there is also a clear trend in the growth of other sources of scientific production in relation to air pollutants, suggesting new research questions regarding the issue of environmental air pollutants and canines (Figure 2).

Although the scientific production of this topic has had a recent appearance in the last five decades, authors such as Sonne, Dietz and Letcher, have managed to consolidate the role of canines as one of the study models that allows the evaluation of environmental pollutants and their effects in dogs, the above according to the impact factor or $H$ index resulting from this scientometric analysis in the author's section. It should be mentioned in this sense that the collaboration between these authors from 2005 (Figure 3) allowed an increase in the number of publications on this subject until 2018, one of the most productive years and the period of maximum consolidation with relation to these themes.

In this sense, the participation of these three authors has allowed the development of important scientific production, such as the reference text: Pets as Sentinels, Forecasters and Promoters of Human Health (Pastorinho and Sousa 2020). One of the most complex texts where the opinion of a large group of experts on the subject of environmental pollutants is compiled, they even touch on different associated topics such as the use of canines for the evaluation of comorbidities and various diseases such as obesity, cancer, immunological alterations, immunomodulation and neurodegenerative alterations that both species share from these types of themes.

Regarding the tripartite graph (Figure 4), there is a clear interconnection between the most cited authors regarding the keywords that were used as input for the development of this analysis (dog and environmental pollutants). However, words such as asthma, exposure and health are likely topics that are beginning to develop as new lines of research that could be related to this topic, as can be seen in the graph of the networks of associations between the words (Figure 7). Also, in the same graph (Figure 4) it is possible to observe that the Universities of Heme and Hokkaido, located in Japan, are leading the top of institutional affiliations that have generated the most contributions in the development and scientific production on issues related to canines and environmental pollutants. Which may be due to the fact that this country has been conducting research related to air pollutants in recent decades and new lines of research such as particulate matter and allergens (Zhang et al. 2019; Wang et al. 2010) due to the problems that are currently related worldwide (Calderon et al. 2001; Selin 2009).

In this same sense, the University of Aarhus located in Denmark continues to be one of the most representative institutional affiliations due to the relationship between the most prominent authors in relation to this topic such as Sonne and Dietz (Pastorinho and Sousa 2020; Sonne et al. 2020). A valid 
explanation for this phenomenon is the thematic interest shared by these authors, when generating scientific production in relation to this research topic, thus producing an increase in the number of collaborations. In this sense and for this scientometric analysis, these authors are undoubtedly the most prominent for the development of research related to canines and environmental pollutants, for which people interested in the development of this type of studies are advised to create collaboration networks with this important nucleus of experts and/or to consult their scientific publications, due to the experience they have gained from the development of their studies.

For this scientometric analysis, the United States, Denmark and Canada were considered the countries with the greatest impact on production and scientific collaboration in relation to the issue of environmental pollutants and their effects on canines. However, it should be clarified that eastern countries such as Japan and China have begun to play an important role in the generation of new scientific knowledge in relation to air pollution issues, particulate matter, and the role that canines would have as models of sentinel studies to these pollutants (Zhang et al. 2020). Similar results have been found in studies in Latin America (Calderon et al. 2001). However, the development of more research studies in relation to air pollutants, chemical pollutants and sentinel study models in Latin America is required, to allow a better development of this important research line, as can be seen for other latitudes of the world (Figure 6).

\subsection{Topics of lasting impacts}

For this scientometric analysis, and according with these results, great advances have been made on the study of environmental pollutants such as polychlorinated biphenyls (PCBs), polybrominated diphenyl ethers (PBDEs), and heavy metals such as mercury and lead, nowadays pollutants high-emission's in urban centers (Pastorinho and Sousa 2020). In this sense the development of these topics has allowed to recognize the use of canines as good candidates for the follow-up and monitoring of the impacts that these pollutants would have on the human being (Calderon et al. 2001). This is due to the short time it takes to show the adverse effects of a wide variety of pollutants and toxins in comparison to humans (Hoffman et al., 2018). This could also be useful for linearity studies that are commonly used in human medicine, due to the similarities that exist between these two species (Lindblad et al., 2005), but mainly to the routes of exposure that seem to be very similar between them. This analysis could also be considered as a first approach of different scientometric analyses that could be carried out in relation to environmental pollutants and canines.

In the keyword analysis, it was possible to identify three groups with different foci. The largest group focuses on air pollution and asthma, in addition to its relationship with the group of caniforms, which probably precedes the effect that air pollution would have on terrestrial mammals such as canines, since it represents the main route of exposure in these animals, being the biomagnification of the terrestrial food chain less marked (Pastorinho and Sousa 2020), contrary to what would happen in aquatic organisms (Seabert et al. 2014). 
The following group includes the effects of halogenated organic pesticides and heavy metals in dogs and sled dogs on organs such as the kidney and liver, this being the most prominent group due to the fact that the effects that these pollutants would have on target organs have been very well documented (Parker et al. 2006; Dunlap et al. 2007; Serpe et al. 2013, Pastorinho and Sousa 2020). Regarding this issue, Sonne et al. 2020 reported in dogs the appearance of persistent pollutants such as PBDEs and $P C B s$, which tend to accumulate on the marine trophic chain, and found high concentrations of these compounds in arctic and circumpolar areas, the above due to the consumption of products based on marine animals. Marine animals would be the main source of exposure in this population, which requires the development of much more studies on different latitudes of the planet to determine if these same results are similar under other environmental conditions.

The third smallest group focuses on biological and chemical contaminants that could be occurring in parallel and additively, and that canine sentinel models could probably better clarify the complex relationship between these issues, as clearly proposed in the scientific production such as the stipulated by Pastorinho and Sousa (2020) and Calderon et al. (2001).

Even though in this analysis there has been a small number of documents related to this topic compared to much more consolidated topics (Lei et al. 2018), it should be noted that in recent years this topic has had an increase in the number of publications when compared to previous years. This is also interesting considering that the number of case reports in the clinical practice are increasing and that usually canines are the first animals to be reported as early-warning systems for humans and other animals in these case reports (Pastorinho et al., 2020).

The most cited references described in this document highlight the relevance of the work of each research team in this area of scientific knowledge. It should be emphasized in the development of this type of studies and the influential role of the respective research teams in the development of these topics. Among them, Sonne et al. 2010, 2011, 2014, 2015; Letcher et al. 2009, 2017; Mizukawa and Nomiyama 2020, Poma et al. 2020 and Pastorinho and Sousa, 2020 draw attention, because they focus their studies specifically on the effect and relationship that canines exposed to different emerging environmental pollutants such as heavy metals, halogenated organic compounds and aromatic hydrocarbons would have on different biomarkers, including on the response of immunological, hepatorenal biomarkers and some endocrine parameters (Hansmann et al. 2009; Chung et al. 2020). In the same way, the role of Asian research that has allowed important advances in recent years in relation to these issues stands out, such as the research contributed by Zhang, Wang and Chen which has addressed important issues such as water quality, biological pollutants, air pollution, gastric toxins, among others (Wang et al. 2010, 2020; Zhang et al. 2019; Chen et al. 2021), investigations that clarify much better the knowledge gaps on these issues as previously discussed, allowing broadening the spectrum of study of environmental pollutants in relation to canines, all of the above through the use of methodologies applied to omics sciences, a field of study less studied in developing countries (Álvarez et al. 2021) . 
In the case of Latin America, a region highly affected by environmental pollutants (Canham et al. 2020), the production of scientific information related to the subject of canines seems to be much lower than the average of publications developed in other regions of the world, being Argentina (Garcia 1974), Chile (Muñoz et al. 2014), Brazil (Scaini et al. 2003) and Uruguay (Mañay et al. 2008) the only representatives identified for this class of studies, this is probably because they are mostly published in Spanish language and were not taken for this analysis (only one typology was found in Spanish for this review in the period covered by this study), being the German and Japanese languages the languages that have been gaining strength in relation to these publications, with a total of 10 and 4 publications for the last three decades correspondingly. Likewise, for this region of the planet the scarce number of collaboration and scientific production in relation to this issue is discussed, this probably due to the little interest or financing that they have had in relation to this problem, despite the fact that it is one of the regions of the world where phenomena related to climate change and pollutants prevail (Canham et al. 2021). However, more searches in other databases are required to confirm the hypotheses raised in this document.

\section{Conclusions}

The annual publications on environmental pollutants in relation to canines have had a significant increase in the last decades worldwide, this mainly due to the increasing efforts to better understand this problem. The present analysis revealed that there are still many information gaps on issues related to the effects of environmental pollutants, in particular relevant topics such as air pollutants, water quality and the atmospheric availability of pollutants on canines. A total of 372 documents were obtained, suggesting this topic as a recently emerging research area that has managed to have a greater participatory approach and interest for its consolidation during the last 2 decades. Among the four main countries with the highest bibliographic production and collaborative production are the United States, Denmark, Japan, and Canada, which can be considered as research powers in the field of environmental pollutants and canines, for which it is recommended to carry out scientific collaboration by new researchers in this area to generate consolidation studies.

The three most productive journals on the subject were Science of the Total Environment, Environmental Science and Technology and Environmental Health Perspectives, considering them as necessary inputs for the search for information in relation to this area, for which we suggest their review at the time of making or propose research related to this topic. On the other hand, the University of Ehme (Japan), the University of Aarhus (Denmark), the University of Hokkaido (Japan) and the University of California (USA), are the most relevant affiliations for the development of this type of research and probably where the most representative authors work on the subject, so for future research we recommend co-authoring with these universities in order to consolidate study projects related to these topics. Regarding the most representative authors on these topics, we find that Sonne, Dietz and Letcher are the main authors who have carried out the most studies on this topic. However, Asian researchers such as Wang, Zhang and Chen have gradually managed to position themselves on recent air pollution issues, a trend in research for future linked studies. Research related to topics such as contamination by PCBs, PBDEs, and heavy metals, are considered for this analysis as a trend due to the negative impact that has been described in 
areas where the bioaccumulation of these compounds in the trophic chain has begun to have consequences both for human and animal health. In the same way, research related to pollution issues appear to increase due to the problems that are currently related worldwide, especially due to atmospheric pollution that is being increasingly studied by different branches of knowledge.

With this review, a first approach was made between this line of research and scientometrics. It is recommended to carry out more in-depth investigations to complete the results of this study, likewise it is recommended for future approaches the use of other databases such as Pubmed or Web of Science, as well as the search for other animal species of environmental study, such as the felines or wild species, which complement the findings found in Scopus in order to join forces that allow a better consolidation of the sentinel animal model and the state of the art in this field of study. Finally, we highlight the importance of scientometric analyzes as necessary inputs that allow us to visualize the behavior, patterns, and trends on a particular topic in a retrospective way on different areas of knowledge, the above with the aim of generating a first approximation between the researcher and his interest in the development and consolidation of any research line.

\section{Declarations}

\section{Acknowledgement}

The authors wish to express their gratitude to Lorena Rojas Sabogal (specialized services professional at the Alfonso Borrero Cabal, S.J. Library of the Pontificia Universidad Javeriana) for her support in the preparation of this article. Also to Orli Avila and her Native American daughters Gabrielle and Emily Salazar for their collaboration and editing in the translation of this article into the English language.

\section{Ethical Approval:}

Not applicable.

\section{Consent to Participate:}

All authors haveread and agreed to the published version of the manuscript.

\section{Consent to Publish:}

We grant the rights to the journal to publish the results of our review, once the reviewers of the same approve it.

\section{Authors Contributions:}

It is confirmed that its publication has been approved by all the co-authors, as well as by the responsible authorities, of the institute where the work has been carried out. Albert Avila (Author, editing, bibliometric analysis);Laura Prieto (Co-author, collaboration, editing) AndreaLuna-Acosta (Co-author, collaboration, form editing, text editing). 


\section{Funding:}

The publisher will not be legally liable for compensation claims

\section{Competing Interests:}

The authors declare no conflict of interest.

\section{Availability of data and materials:}

Two files related to the Top four most cited local sources are attached, and another file in relation to the Scopus database that was used in Bibliometrix of $\mathrm{R}$ for the execution of bibliometric analyses.In addition, the data that support the findings of this study are available from thecorresponding author upon request

\section{References}

1. Abbott L (2017) The Effects of Environmental Mercury Contamination on Wild and Domestic Animals. Approaches in Poultry, Dairy \& Veterinary Sciences 1(2):25-27. https://doi.org/10.31031/APDV.2017.01.000507 .

2. Alvarez R, De la fuente $M$, Montalvo L, Hidalgo $A$ (2021) Challenges of diagnosticgenomics in LatinAmerica. Current Opinion in Genetics \& Development 66 (2): 101-109. https://doi.org/10.1016/j.gde.2020.12.010.

3. Andreoli V, Francesca S (2017) Genetic Aspects of Susceptibility to Mercury Toxicity: An Overview. International Journal of Environmental Research and Public Health 14(1): 93. https://doi.org/10.3390/ijerph14010093.

4. Aria M, Cuccurullo C (2017) Bibliometrix: An R-tool for exhaust science mapping analysis. Journal of Informetrics 11 (4): 959-975.

5. Beck A, Lash M, Jason B (2020) Environmental Toxic Exposures Using Companion Animals as an Indicator of Human Toxicity: A Case Report and Discussion.Journal of Emergency Medicine 59(1): 1-7. ttps://doi.org/10.1016/j.jemermed.2020.04.026.

6. Benavent R, Gonzales D, Castello C, Navarro M, Alfonso A, Vidal A, Dominguez L (2017) Bibliometría e indicadores de actividad científica (V) Indicadores de colaboración Acta Pediatrica Especializada 75 (9-10):108-113.

7. Berriel C, Henriquez LA, Octavio P (2020) Role of Pet Dogs and Cats as Sentinels of Human Exposure to Polycyclic Aromatic Hydrocarbons. In: Pastorinho and Sousa (Eds) Pets as Sentinels of Human Exposure to Environmental Contaminants. Springer, Switzerland. 65-81. https://doi.org/10.1007/9783-030-30734-9.

8. Bobb J, Valeri L, Claus Henn B, Christiani D, Wright R, Mazumdar M, Godleski J, Coull B (2015) Bayesian kernel machine regression for estimating the health effects of multi-pollutant mixtures. Biostatistics 16(3):493-508. https://doi.org/10.1093/biostatistics/kxu058. 
9. Boisvert G, Sonne C, Rigét F, Dietz R, Letcher R (2019) Bioaccumulation and biomagnification of perfluoroalkyl acids and precursors in East Greenland polar bears and their ringed seal prey. Environ Pollut Part B 252:1335-1343. https://doi.org/10.1016/j.envpol.2019.06.035.

10. Calderon L, Mora A, Fordham L, Chung C, Garcia R, Osnaya N, Hernandez J, Acuña H, Gambling M, Villarreal A, Carson J, Koren H and Devlin R (2001) Canines as Sentinel Species for Assessing Chronic Exposures to Air Pollutants: Part 1. Respiratory Pathology. Toxicological Sciences 61:342355.

11. Canham, R, González. A, Elliott. J (2021) Mercury Exposure and Toxicological Consequences in Fish and Fish-Eating Wildlife from Anthropogenic Activity in Latin America. Integrated Environmental Assessment and Management 17(1):13-26. https://doi.org/10.1002/ieam.4313.

12. Carriquiriborde, P. (2021). Principios de Ecotoxicologia. Facultad de ciencias exactas. Editorial de la universidad de la plata. Libros de cátedra.

13. Chen C,LiS,Yan F, Li G, Zhang W, Liu J, JiaX (2007) Factors associated with the diagnosis of neurodevelopmental disorders: A population-based longitudinal study. Pediatrics 119(2):435-443. https://doi.org/10.1542/peds.2006-1477.

14. Chen L, Liu J, Hu W, Gao J, YangJ (2021) Vanadium in soil-plant system: Source, fate, toxicity, and bioremediation. Journal of Hazardous Materials 405 https://doi.org/10.1016/j.jhazmat.2020.124200.

15. Chibunda, R. and Janssen, C (2009) Mercury residues in free-grazing cattle and domestic fowl form the artisanal gold mining area of Geita district, Tanzania. Food AdditContam Part AChem Anal Control Expo Risk Assess. 26 (11):1482-7. https://doi.org/10.1080/02652030903114928

16. Chung S, Li Y, Lin L (2020) Radiographic findings and pathology of a dogwith mercury toxicity. Forensic imaging 12:23. https://doi.org/10.1016/j.fri.2020.200421.

17. Córdoba D(2006) Toxicología. 5th Ed. El Manual Moderno, Bogotá Colombia. ISBN 9789589446164.14.

18. Dhital S, Rupakheti D (2019) Bibliometric analysis of global research on air pollution and human health: 1998-2017. Environ SciPollut Res Int. 26(13):13103-13114. https://doi.org/10.1007/s11356019-04482-x.

19. Dunlap K, Duffy L, Reynolds A, Gerlach S (2007) Hair analysis in sled dogs (Canis lupus familiaris) illustrates a linkage of mercury exposure along the Yukon River with human subsistence food systems. Science of the Total Environment 385(1-3): 80-85.

https://doi.org/10.1016/j.scitotenv.2007.07.002.

20. Eccles K, Littlewood E, Thomas P, Chan H (2019) Distribution of organic and inorganic mercury across the pelts of Canadian river otter (Lontracanadensis). Scientific Reports Springer US 9(1): 112. https://doi.org/10.1038/s41598-019-39893-w

21. Ellis, E (2011) Anthropogenic transformation of the terrestrial biosphere. Philosophical Transactions of the Royal Society 369:1010-1035. https://doi.org/10.1098/rsta.2010.0331. 
22. Espejo W, Celis J, Chiang G, Bahamonde P (2020) Environment and COVID-19: Pollutants, Impacts, Dissemination, Management and Recommendations for Facing Future Epidemic Threats. Science of the Total Environment 74: 141314. https://doi.org/10.1016/j.scitotenv.2020.141314.

23. Fuentes F, Herrera C, Pinedo J, Marrugo J, Díez S (2018) Assessment of human health risk associated with methylmercury in the imported fish marketed in the Caribbean. EnvironmentalResearch 165 (1): 324-329. https://doi.org/10.1016/j.envres.2018.05.001.

24. Garcia J (1974) Estudios y comentarios sobre impregnación humana por plaguicidas organoclorados en la república argentina. Medicina 34(4):393-410. PMID: 4607834.

25. Guzzi G, Ronchi A, De Marco B, Pigatto P, Passoni M (2018) Mercury distribution from blood to hair in humans and dogs Gianpaolo. Journal of Clinical Toxicology 8(1):3-5.

26. Hansmann I, Stephan A, Wirtz A, Gruber P (2009) Mercury poisoning in a German shepherd dog. Vet. Rec. 165: 447-448. https://doi.org/doi: 10.1136/vr.165.15.447.

27. Harzing A, Alakangas S (2016) Google Scholar, Scopus, and the Web of Science: A Longitudinal and Cross-Disciplinary Comparison. Scientometrics 106: 787-804. https://doi.org/10.1007/s11192-0151798-9.

28. Ipenza C (2012) Manual Para entender la pequeña minería y la mineria artesanal y los decretos legislativos vinculados a la minería ilegal. 2ndEdn, Edited by J. Dammert. Lima-Perú.

29. Kirkegaard M (2009) Effects of long-term dietary exposure to organohalogen contaminants on vitamin and hormone status in the Greenland Sledge dog (Canisfamiliaris). PhD thesis. Dept. of Arctic Environment, NERI. National Environmental Research Institute, Aarhus University, Denmark and Faculty of Health Sciences, University of Southern Denmark. http://www.dmu.dk/Pub/ PHD_ MKI.pdf.

30. Laks D (2009) Assessment of Chronic Mercury Exposure and Neurodegenerative Disease. M.S Thesis, U. C. Berkeley.

31. Lei J, Hui-ZhenFuandYuh-Shan Ho (2018) A global perspective of bioaccumulation research using bibliometric analysis, COLLNET Journal of Scientometrics and Information Management, 12(2): 327341.https://doi.org/10.1080/09737766.2018.1501923

32. Letcher R, Chu S, Smyth S (2020) Side-Chain Fluorinated Polymer Surfactants in Biosolids from Wastewater Treatment Plants. Journal of Hazardous Materials388:122044. https://doi.org/10.1016/j.jhazmat.2020.122044.

33. Letcher R, Morris A, Dyck M, Sverko E, Reiner E, Blair D, Chu S, Shen Li (2017) Legacy and new halogenated persistent organic pollutants in polar bears from a contamination hotspot in the Arctic, Hudson Bay Canada: 610-611. https://doi.org/10.1016/j.scitotenv.2017.08.035.

34. Letcher R, Bustnes J, Dietz R, Jenssen B, Jørgensen E, Sonne C, Verreault J, Vijayan M, Gabrielsen G (2009) Exposure and effects assessment of persistent organohalogen contaminants in arctic wildlife and fish. Sci Total Environ. 15: 2995-3043. https://doi.org/10.1016/j.scitotenv.10.038.

35. Mañay N, Cousillas A, Alvarez C, Heller T (2008) Lead contamination in Uruguay: the "La Teja" neighborhood case. Reviews of environmental contamination and toxicology 195: 93 - 115. PMID: 
18418955.

36. Mizakawa H, Nomiyama K (2020) Biotransformation of Brominated Compounds by Pet Dogs and Cats. In: Pastorinho and Sousa (Eds) Pets as Sentinels of Human Exposure to Environmental Contaminants. Springer, Switzerland. 107-121. https://doi.org/10.1007/978-3-030-30734-9.

37. Moraes R, Morel L, Correa M, Lima G (2020) A Bibliometric Analysis of Articles Published in Brazilian Dental Journal over 30 years.Braz. Dent. J. 31(1). https://doi.org/10.1590/0103-6440202004550.

38. Muñoz C, Mason M, Encina C, Astroza A. Romero A. (2014) Leptospira contamination in household and environmental water in rural communities in southern Chile. International Journal of Environmental Research and Public Health 11 (7): 6666 - 6680. https://doi.org/10.3390/ijerph110706666.

39. Nikolovski G, Atanaskova E (2011) Use of canine hair samples as indicators of lead and cadmium pollution in the Republic of Macedonia. Bulgarian Journal of Veterinary Medicine 14(1): 57-61. https://doi.org/10.5455/vetworld.2011.368-370.

40. NRC (1991) Animals as Sentinels of Environmental Health Hazards. National Research Council (US) Committee on Animals as Monitors of Environmental Hazards. National Academies Press. Washington, DC. ISBN-10: 0-309-04046-9.

41. Obiri S, Yeboah P, Osae S, Cobbina S, Armah F, Ason B, Antwi E, Quansah R. (2016) Human health risk assessment of artisanal miners exposed to toxic chemicals in water and sediments in the presteahuni Valley district of Ghana. International Journal of Environmental Research and Public Health 13(1):139. https://doi.org/10.3390/ijerph13010139.

42. Oddone, A. and Rodriguez, P. (2010) Enfermedades congénitas y hereditarias de las razas caninas y felinas. Intermedical Editorial. Buenos Aires Argentina. ISBN 978-950-55-382-2.

43. Oost R, Beyer J, Vermeulen N (2016) Soil Quality Field Kit: Part II, Environmental Toxicology and Pharmacology 13(2):57-149.

44. Ostrander, E. and Wayne, R. (2005) The canine genome. Genome Res. 15(12):1706-16. https://doi.org/10.1101/gr.3736605.

45. Park S, Lee M, Kim S, Al P (2004) Studies on Cd, Pb, Hg and Cr Values in Dog Hairs from Urban Korea. Asian-Australasian Journal of Animal Sciences 18(8):1135-1140. https://doi.org/10.5713/ajas.2005.1135.

46. Parker H, Meurs K, Ostrander E (2006) Finding cardiovascular disease genes in the dog.Journal of veterinary cardiology the official journal of the European Society of Veterinary Cardiology 8(2):115127. https://doi.org/10.1016/j.jvc.2006.04.002.

47. Pastorinho M, Sousa A (2020) Pets as sentinels, forecasters, and promoters of human health.Springer, Switzerland. https://doi.org/10.1007/978-3-030-30734-9v.

48. Pastorinho MR, Sousa AC (2020) Pets as Sentinels of Human Exposure to Neurotoxic Metals. In: Pastorinho and Sousa (Eds) Pets as Sentinels of Human Exposure to Environmental Contaminants. Springer, Switzerland. 83-106. https://doi.org/10.1007/978-3-030-30734-9. 
49. Poma G, Malarvannan G, Covaci A (2020) Pets as Sentinels of Indoor Contamination. In: Pastorinho and Sousa (Eds) Pets as Sentinels of Human Exposure to Environmental Contaminants. Springer, Switzerland. 3-20. https://doi.org/10.1007/978-3-030-30734-9.

50. Pranckute R (2021) Web of Science (WoS) and Scopus: The Titans of Bibliographic Information in Today's Academic World. Publications 9 (12):1. https://doi.org/10.3390/ publications 9010012.

51. Scaini C, De Toledo R, Lovatel R, Dionello M, Dos Anjos F, Susin L, Mendoza V (2003) Environmental contamination by helminth eggs and larvae in dog feces from central area of Cassino Beach, Rio Grande do Sul. Revista da Sociedade Brasileira de Medicina Tropical 36(5):617 - 619. https://doi.org/10.1590/s0037-86822003000500013.

52. Schutzmeier P, Berger U, Bose-O'reilly S (2017) Gold mining in ecuador: A cross-sectional assessment of mercury in urine and medical symptoms in miners from Portovelo/Zaruma. International Journal of Environmental Research and Public Health 14(1): 2-15. https://doi.org/10.3390/ijerph14010034.

53. Seabert T, Pal B, Pinet F, Haman M, Robidoux P, Imbeault E, Krümmel L, Kimpe L, (2014) Elevated contaminants contrasted with potential benefits of $v-3$ fatty acids in wild food consumers of two remote first nations communities in Northern Ontario, Canada. PLoS ONE 9: 90351. https://doi.org/10.1371/journal.pone.0090351.

54. Selin NE (2009) Global Biogeochemical Cycling of Mercury: A Review. Annual Review of Environment and Resources 34(1): 43-63. https://doi.org/10.1146/annurev.environ.051308.084314.

55. Serpe F, Russo R, Simone A, Florio S, Esposito M, Severino L (2012) Levels of heavy metals in liver and kidney of dogs from urban environment. Open Veterinary Journal 2 (4):15-18. PMID: 26623285.

56. Shapiro K (1997) A phenomenological approach to the study of nonhuman animals. In Mitchell R, Thompson N, Miles L (eds.), Anthropomorphism, anecdotes, and animals. Albany, NY. 277-296.

57. Sonne C (2010) Health effects from long-range transported contaminants in Arctic top predators: an integrated review based on studies of polar bears and relevant model species. Environ Int 36:461491. https://doi.org/10.1016/j.envint.2010.03.002.

58. Sonne C, Leifsson P, Iburg T, Dietz R, Born E, Letcher R, Kirkegaard M (2011) Thyroid gland lesions in organohalogen contaminated East Greenland polar bears (Ursusmaritimus). Toxicol Environ Chem 93:789-805. https://doi.org/10.1080/02772248.2011.558669.

59. Sonne C, Kirkegaard M, Jacobsen J, Jenssen BM, Letcher RJ, Dietz R (2014) Altered 25hydroxyvitamin D3 in liver tissue from Greenland sled dogs (Canisfamiliaris) dietary exposed to organohalogen polluted minke whale (Balaenopteraacuterostrata) blubber. Ecotoxicol Environ Saf 104:403-408. https://doi.org/10.1016/j.ecoenv.2013.11.017.

60. Sonne C, Letcher R, Bechshøft T, Rigét F, Muir D, Leifsson P, Born E, Hyldstrup L, Dietz R, Rigét F, Letcher R, Munk Pedersen K, Styrishave B (2014) Steroid hormones in blood plasma from Greenland sled dogs (Canisfamiliaris) dietary exposed to organohalogen polluted minke whale (Balaenopteraacuterostrata) blubber. Toxicol Environ Chem 96:273-286. https://doi.org/10.1080/02772248.2014.924195. 
61. Sonne C, Gustavson K, Dietz R, Letcher R (2015) Physiologically based pharmacokinetic modelling and verification of distribution, elimination and bioaccumulation of persistent organic pollutants in Greenland sledge dogs (Canisfamiliaris). Environ Res 140: 45-55. https://doi.org/10.1016/j.envres.2015.06.034.

62. Sonne C, Letcher R, Bjorn J et al (2020) Sled Dogs as Sentinel Species for Monitoring Arctic Ecosystem Health. In: Pastorinho and Sousa (Eds) Pets as Sentinels of Human Exposure to Environmental Contaminants. Springer, Switzerland. 21-45. https://doi.org/10.1007/978-3-03030734-9.

63. Sumner R, Imogen T, Morne Van Der M, Andrew B, Gary C, Lea R (2020) The Dog as a Sentinel Species for Environmental Effects on Human Fertility. Reproduction 159(6):165-276. https://doi.org/10.1530/REP-20-0042.

64. Sweileh W, (2020) Bibliometric analysis of peer-reviewed literature on climate change and human health with an emphasis on infectious diseases. Global Health 16 (44). https://doi.org/10.1186/s12992-020-00576-1

65. Thompson L, Wageh S (2019) Environmental Chemical Contaminants in Food: Review of a Global Problem. Journal of Toxicology 2345283:14. https://doi.org/10.1155/2019/2345283.

66. Toyomaki H, Yabe J, Shouta M. et al. (2020) Factors Associated with Lead (Pb) Exposure on Dogs around a Pb Mining Area, Kabwe, Zambia. Chemosphere 247:125884. https://doi.org/10.1016/j.chemosphere.2020.125884.

67. Wang J, Solo H, Abdelzaher A, Fleming L (2010) Estimation of enterococci input from bathers and animals on a recreational beach using camera images. Marine Pollution 60 (8):1270 - 1278. https://doi.org/10.1016/j.marpolbul.2010.03.016.

68. Wang T, Jianzhu M, Andrew N, Hogan S, Katherine L, Brian T, Jason F, Kreisberg P, Adams et al. (2020) Quantitative Translation of Dog-to-Human Aging by Conserved Remodeling of the DNA Methylome. Cell Systems 11(2):176-185. https://doi.org/10.1016/j.cels.2020.06.006.

69. Wang J, Liuwei D, Yining C, Yong S, Filip M, Tack J, O'Connor D (2020) Remediation of mercury contaminated soil, water, and air: A review of emerging materials and innovative technologies. Environment International 134:105281. https://doi.org/10.1016/j.envint.2019.105281.

70. Zhang D, Fu H, \& Ho Y. (2017) Characteristics and trends on global environmental monitoring research: a bibliometric analysis based on Science Citation Index Expanded. Environ SciPollut Res. 24: 26079-26091. https://doi.org/10.1007/s11356-017-0147-3

71. Zhang Y, Hou D, O'Connor D, Shen Z, Shi P, Ok Y, Wen Y, Luo M (2019) Lead contamination in Chinese surface soils: source identification, spatial- temporal distribution and associated health risks. Crit Rev Environ SciTechnol 49(15): 1386-1423. https://doi.org/10.1080/10643389.2019.1571354.

72. Zhu J, Liu W (2020) A Tale of Two Databases: The Use of Web of Science and Scopus in Academic Papers. Scientometrics 123: 321-335. https://doi.org/10.1007/s11192-020-03387-8.

\section{Figures}




\section{Annual Scientific Production}

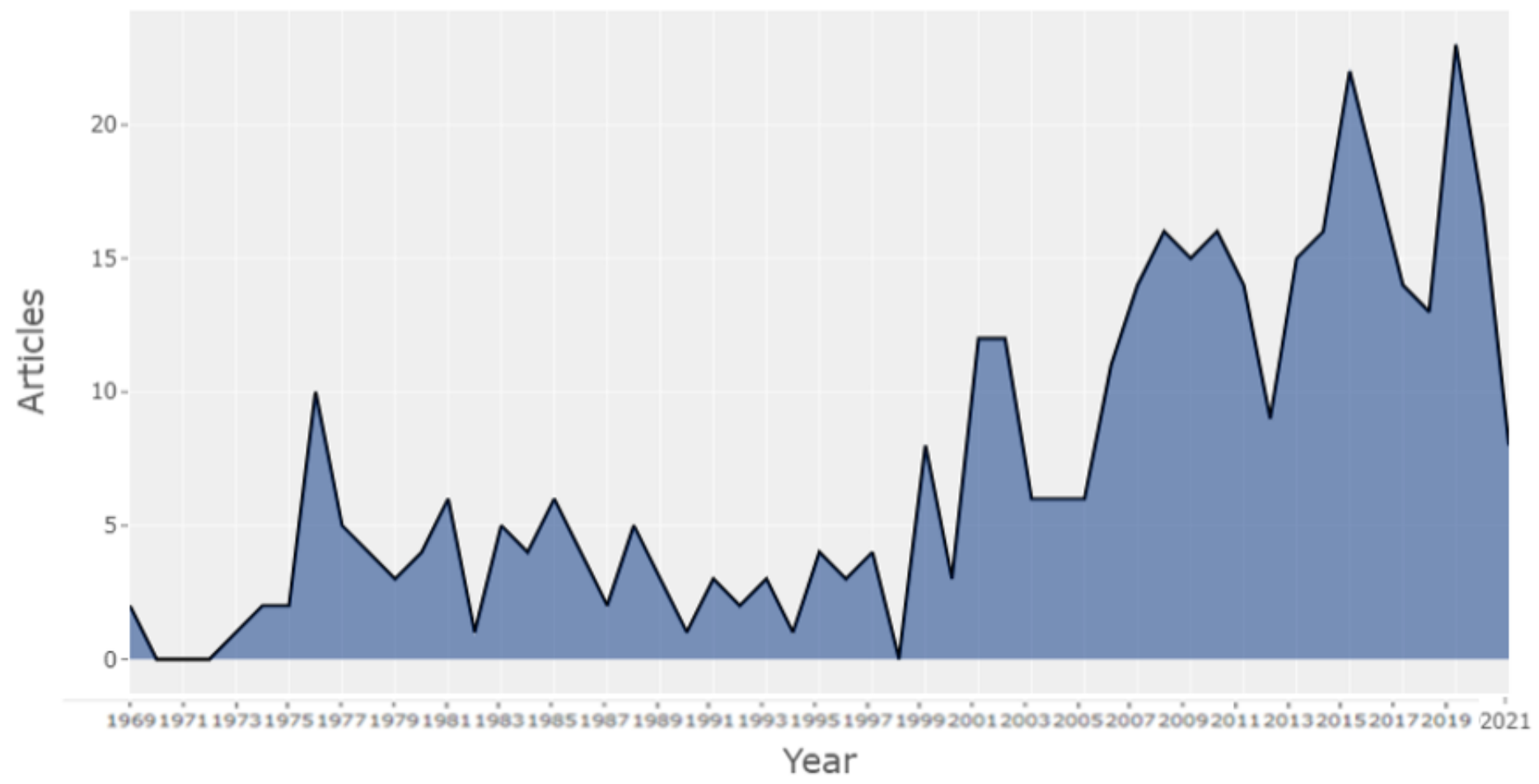

Figure 1

Annual scientific production on research related to environmental pollutants in the canine species from 1969 to 2021 


\section{Bradford's Law}

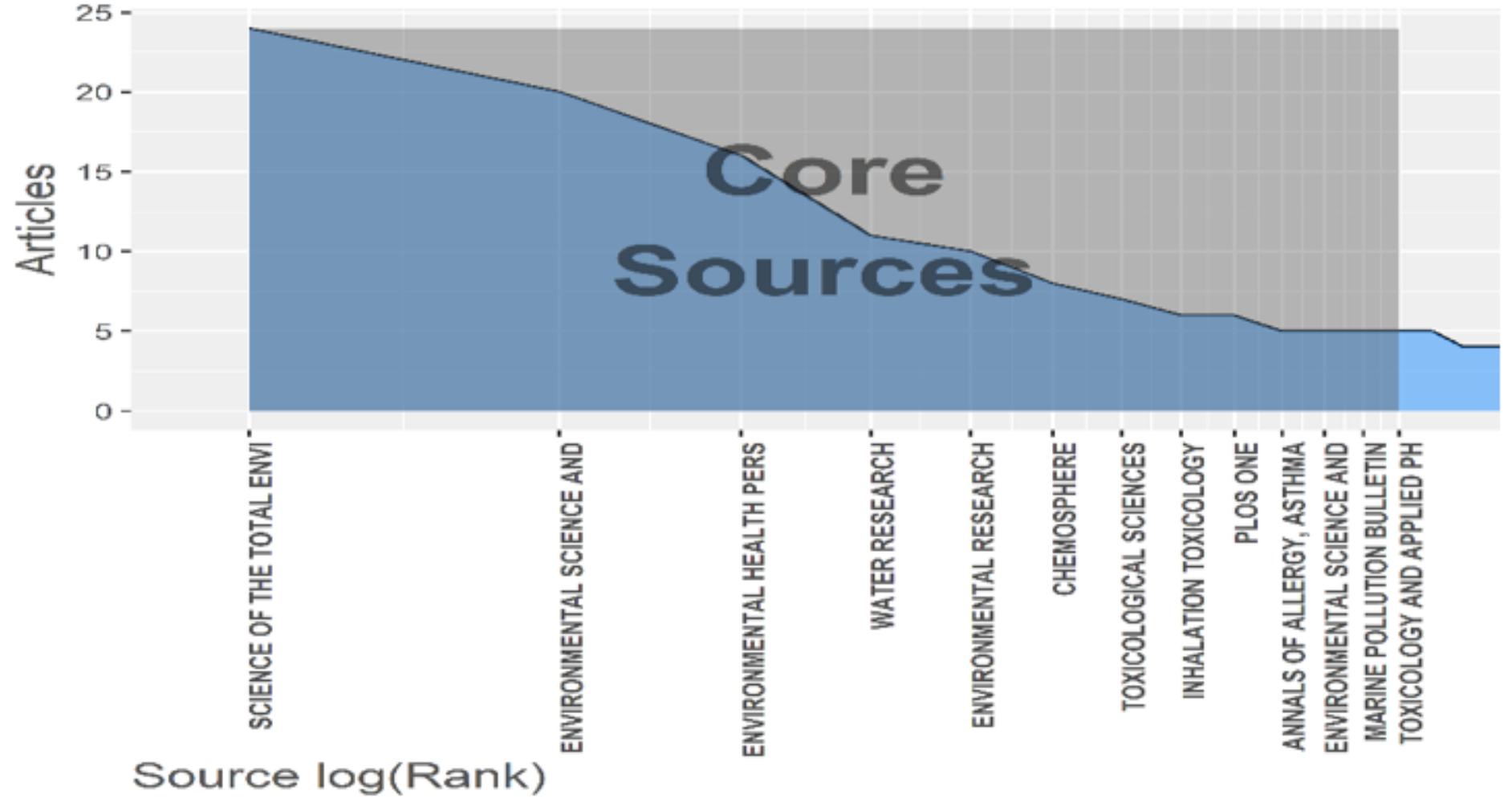

Figure 2

Most relevant publication sources determined according to Bradford's law of dispersion of the scientific literature

\section{Top-Authors' Production over the Time}

SONNE C -

DIETZR -

LETCHER RJ -

TANABE S -

$\stackrel{\text { 흔 }}{\stackrel{\text { 는 }}{4}}$

NOMIYAMA K-

HEYDER J -

KIRKEGAARD M -

MIZUKAWA H -

PHIPATANAKUL $W$ -

KUNISUE T -

$$
\text { 'ั }
$$

N.Articles

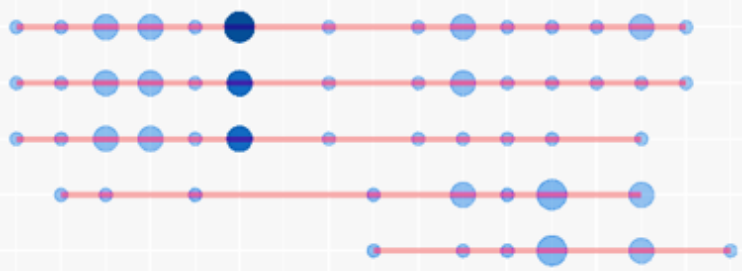

$\bullet$

- 2

3

4

- 5

TC per Year

- 0

- 10

- 20

- 30

- 40

- 50

Figure 3 
Production of the 10 main authors over time. The straight lines indicate the continuity of studies in relation to time

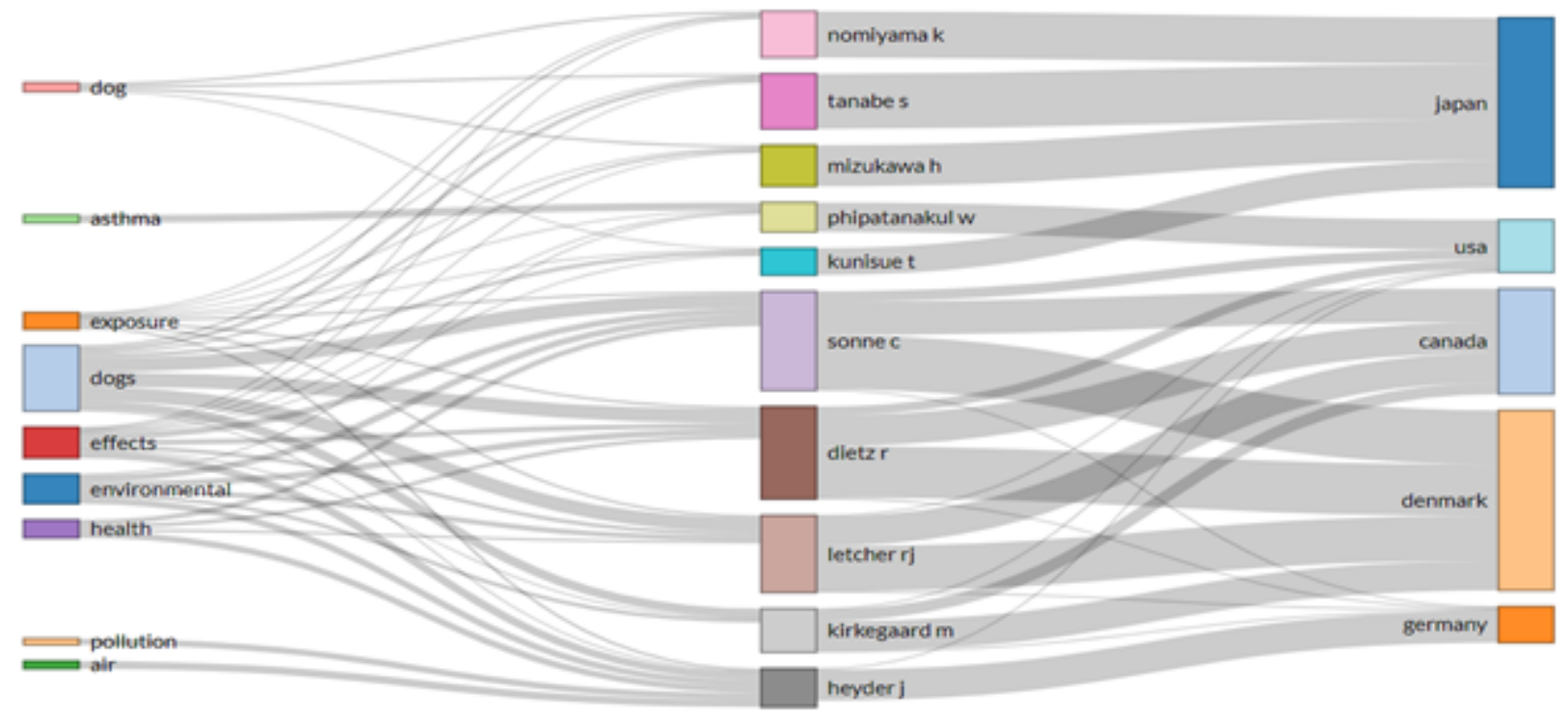

\section{Figure 4}

Tripartite graph on the effects of environmental pollutants on canines. Left field (Keywords), Middle field (Authors), Right field (Countries)

\section{Most Relevant Affiliations}

EHIME UNIVERSITY

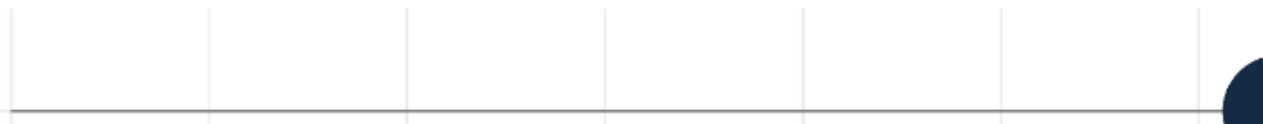

AARHUS UNIVERSITY

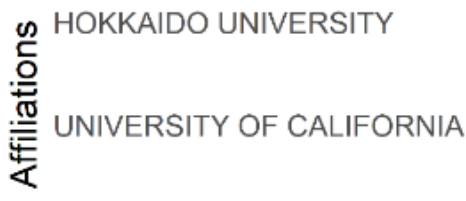

CARLETON UNIVERSITY

HARVARD MEDICAL SCHOOL

UNIVERSITY OF COPENHAGEN

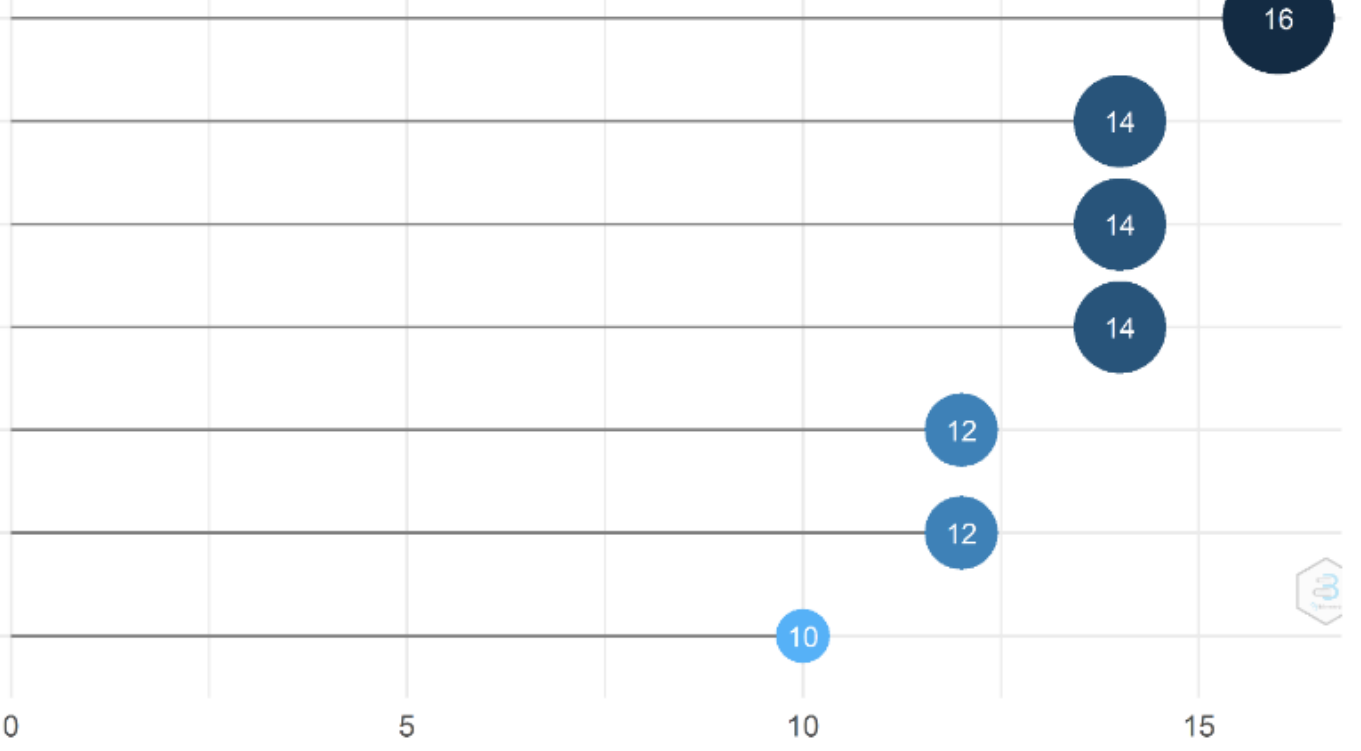

Articles

\section{Figure 5}

Most important affiliations for the development of this kind of studies 


\section{Country Collaboration Map}

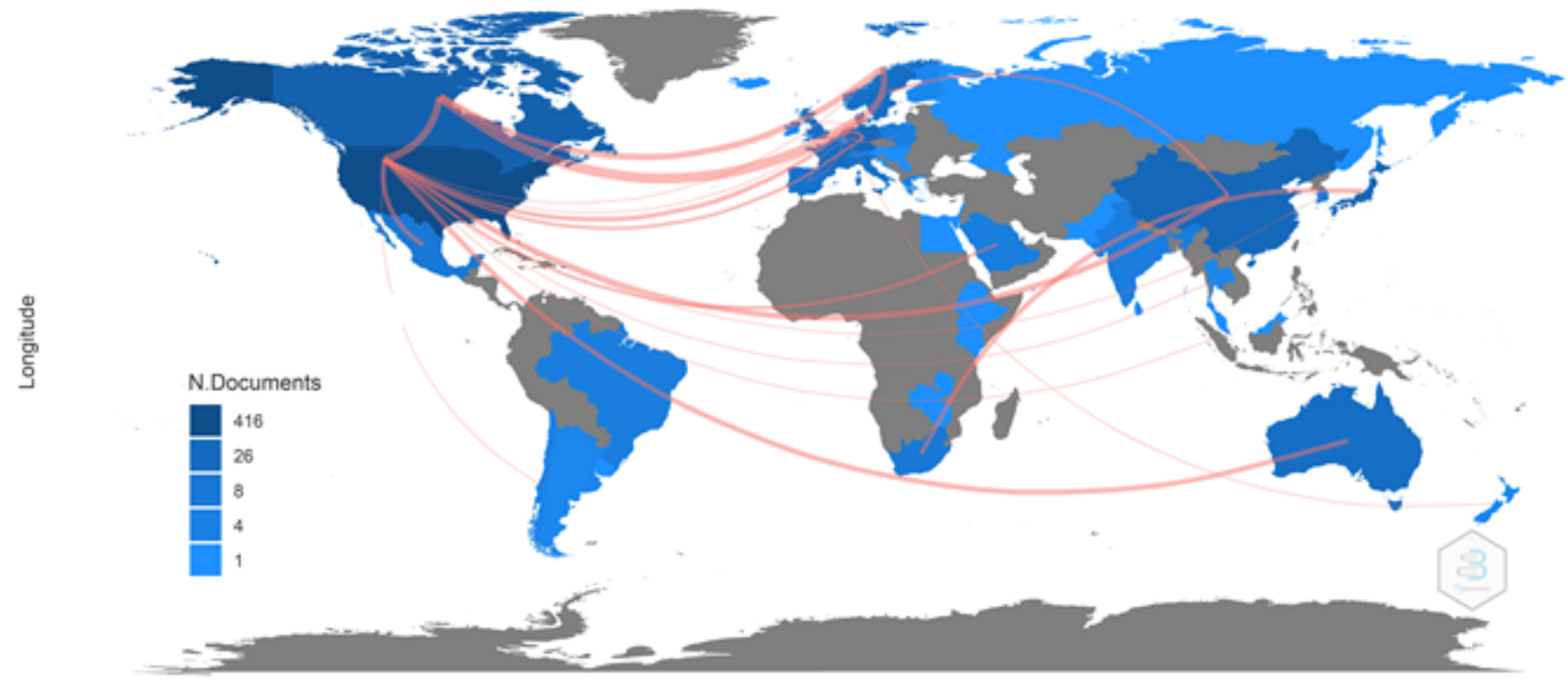

Latitude

\section{Figure 6}

Map of production and collaboration between countries. The edges indicate the networks of nodes that exist between countries for the development of this type of research; the thicker lines indicate the existence of a stronger collaboration between countries. The conventions on the left side indicate the average number of documents produced for each country

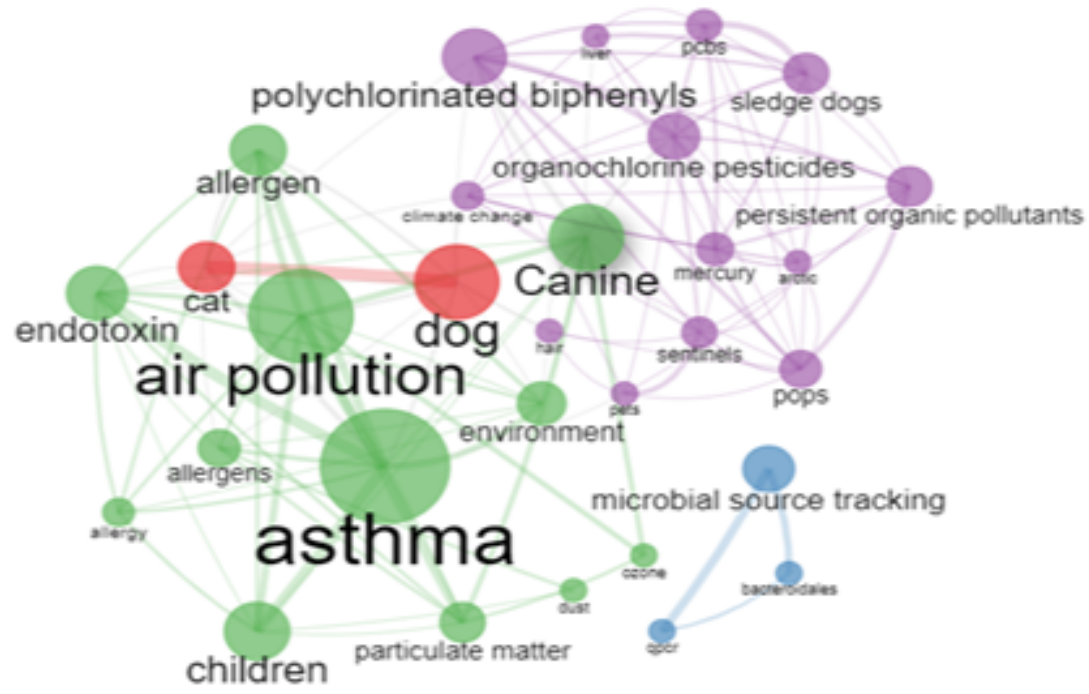

Figure 7

Association networks between the words most used by the authors between 1963 and 2021 


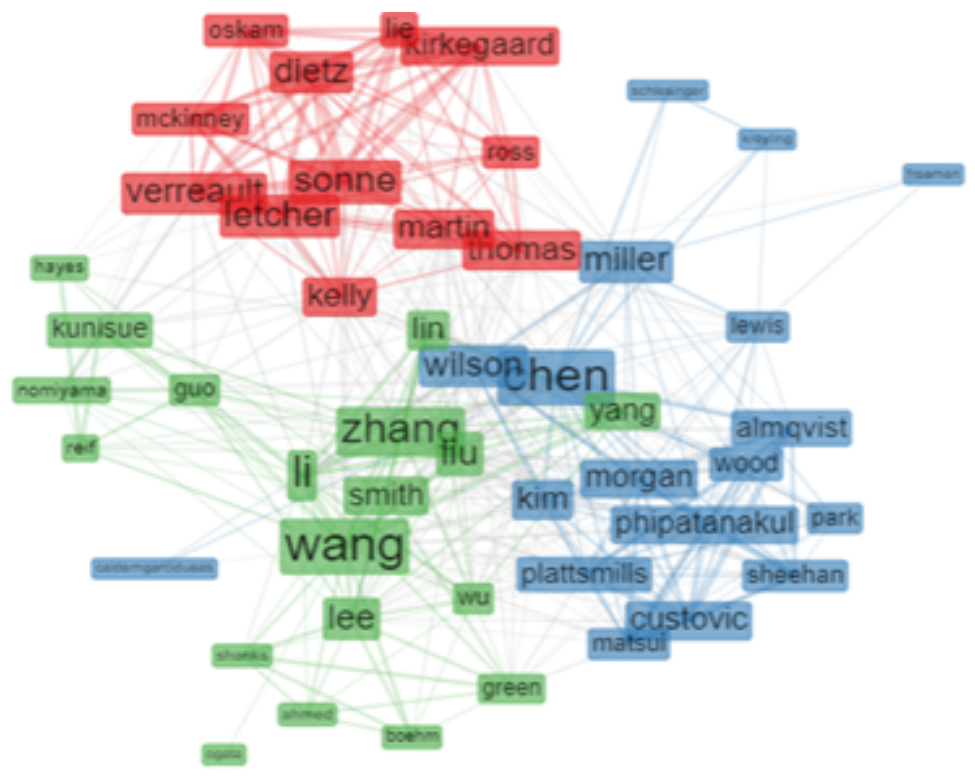

Figure 8

Citation networks on the effects of environmental pollutants on canines between 1963 and 2021

\section{Supplementary Files}

This is a list of supplementary files associated with this preprint. Click to download.

- Annexes.docx

- AnnexTwoDecadesofInformationonCanineEnvironmental.pdf 